\title{
B.A.S.E. - A Brand-Architecture Strategy Explorer
}

Andreas Strebinger, (Andreas.Strebinger@wu-wien.ac.at), Vienna University of Economics and Business Administration Austria

\begin{abstract}
Some of the most pressing brand-related problems concern the management of a system of several brands, i.e. brand architecture, rather than one individual brand. By integrating three fields of theory, (a) the theory of strategic brand concepts, (b) the theory of human information processing and (c) a typology of brand architecture strategies, this paper proposes an explorative instrument from which to derive optimal brand architecture strategies.
\end{abstract}

\section{Introduction}

Having a strong brand that can be clearly recognized by customers is today considered one of the most important components of company value. According to a study conducted by PricewaterhouseCoopers in 1999, 62\% of company value in the FMCG sector and 53\% of the value of companies dealing in durables is considered dependent on brand value. The Boston Consulting Group estimates this value at an even higher 75\%. Management consequently devotes a great deal of attention to building, managing and nurturing brands. Over the past few decades, academic research has managed to develop a comprehensive instrument to support brand management in addressing a host of issues.

Some of the most pressing brand-related problems more often than not concern the management of a system of several brands rather than one individual brand, be it a portfolio of several brands in isolation or a complex brand architecture of several connected members of a brand family. There are a number of reasons why the brand architectures of many companies are becoming increasingly complex:

- $\quad$ Many product categories are in the maturity stage. The fact that consumer preferences are becoming increasingly heterogeneous is forcing many companies towards greater product differentiation.

- Growth in mergers and acquisitions - presumably interrupted only short-term by recessions - has heightened the need to merge not only different corporate cultures, but also different brand portfolios in a way that makes good business sense.

- $\quad$ The Internet has provides an opportunity to build pure e-brands and to develop existing brands into eenabled offline brands.

- The increasing demands of shareholders have also heightened pressure to improve the efficiency of marketing, not least with a view to creating a cost-effective brand structure. Many international brand manufacturers are rethinking or, rather, streamlining their brand architecture for this very reason.

At present, neither academic research nor management consulting seem to have found a compelling theory capable of providing standard strategies for designing brand architectures. Building on a critical analysis of existing literature, this article aims to contribute to the development of such a theory by combining three fields of theory, (a) the theory of strategic brand concepts (C. Whan Park, Bernard J. Jaworski, and Deborah J. MacInnis), (b) the theory of human information processing, in particular dual-process models (e.g. Shelly Chaiken, Wendy Wood, and Alice Eagly; Seymour Epstein; Richard E. Petty and John T. Cacioppo) and (c) a typology of brand architecture strategies (for example, leading on from David A. Aaker and Erich Joachimsthaler; Jean-Noel Kapferer; Kevin Lane Keller).

Readers with comments or questions are encouraged to contact the authors via email. 


\section{Previous Research}

These considerations stem from the matrix of product and/or service categories and target groups or markets in which companies operate. To operate the matrix, the brand architecture strategy has to specify the number of and interrelation between brands. There are five strategies representing ideal types from which to select (Fig. 1):

1. The corporate brand strategy (subsequently abbreviated to "C-branding"), which adopts a uniform brand for all product categories and target groups. As this uniform brand is frequently synonymous with the name of the company, the term corporate brand is used, even if the uniform brand used occasionally differs from the company name; ${ }^{1}$

2. The product brand strategy ("P-branding"), where each product category has its own brand name. These P-brands have no recognizable connection for the customer. One and the same brand name is used for all target groups within the product category. This P-branding strategy can be based on a fine distinction between product categories, resulting in product brands in the narrower sense, or to a more general classification of product categories ("line" or "range brands", e.g. Kapferer, page 188);

3. The target group brand strategy ("T-branding"), where the company targets each target group with a separate brand name, which stands for a number of products;

4. The product and target-group-specific brand strategy ("PT-branding"), where each field in the matrix is given its own brand name; and finally

5. The brand family strategy ("F-branding"), where hierarchically ranked brand names have a "family name", together with a certain number of subbrands with their own "first names". These brand families can also include more than two hierarchical levels and differ from the C-branding strategy in that the subbrands are not merely given purely generic product descriptions, but have registered brand names, which are generally promoted individually. These subbrands can be P-brands, T-brands or PT-brands.

Research to date has taken two differing approaches in addressing the question of identifying a preferable strategy. The first strain of research has a strong psychological slant and focuses on the question of brand and line extensions (e.g. Susan M. Broniarczyk and Joseph W. Alba; Keller and Aaker; Maureen Morrin; Park, Milberg, and Lawson; Deborah Roedder John, Barbara Loken, and Christopher Joiner; Daniel C. Smith and C. Whan Park; Mary Sullivan). This strain has a strong empirical basis, but usually focuses on a case limited to two products or (sub)brands. This approach therefore lacks a system-oriented perspective, in which all the products and target markets the company has are related to one another.

The second strain of research classifies different brand architecture strategies for all or for a majority of products and target markets, and assesses their advantages and disadvantages (e.g. Aaker and Joachimsthaler, page 95; Kapferer, page 187; Keller). These approaches generally take strategic corporate objectives into consideration and benefit from the varied experiences of their advocates. One of the core conclusions drawn from research to date is that separative brand architectures such as P-branding, T-branding or - in extreme cases - PT-branding, all of which work with a considerable number of isolated brands, require compelling reasons (cf. Aaker and Joachimsthaler, page 123; Kapferer, page 209), as more closely integrated brand architectures such as C-branding or F-branding generally offer a greater degree of efficiency and effectiveness (e.g. Sylvia Laforet and John Saunders 1999). This is because synergy effects derived through brand awareness, brand image and brand trust as well as through the transfer of customer loyalty lead to reduced costs of brand communication per unit sold. From the market perspective, the central justification for separate brand architecture strategies is the incompatibility of product or user images. Although advocates of this second strain of research have made excellent contributions to the psychological role of the brand from a customer perspective, their recommendations regarding brand architecture strategies seem to lack a

\footnotetext{
${ }^{1}$ I developed my own terminology due to inconsistencies in the relevant literature. For example, the term "umbrella branding" is frequently used to describe the strategy referred to here as C-branding (e.g. Tülin Erdem; Kapferer; John Saunders and Fu Guoqun; Vanitha Swaminathan, Richard J. Fox, and Srinivas K. Reddy), but also for F-Branding (e. g., Sullivan), which, in turn, is also known as "source brand" strategy elsewhere (e.g. Kapferer). The terminology used by David A. Aaker and Erich Joachimsthaler describes C-branding as "branded house"; F-branding corresponds - depending on the strength of the link between parent and subbrand - to the "subbrands" and "endorsed brands" strategies. However, this otherwise very successful classification fails to differentiate terminologically (not in terms of content) between P-, T- and PT-branding, which Aaker and Joachimsthaler summarise as the "House of Brands" strategy. As the distinction between P-, T- and PT-branding is significant in this paper, the terminology used by Aaker and Joachimsthaler has not been adopted in this case.
} 
sound theoretical basis. This paper aims to close this gap by combining the aforementioned classification of different brand architecture strategies with the theory of strategic brand concepts (Park, Jaworski, and MacInnis) and the theory of human information processing, particularly dual-process models (e.g. Chaiken, Wood, and Eagly; Epstein; Petty and Cacioppo).

Figure 1: Brand architecture strategies

\section{C-branding}

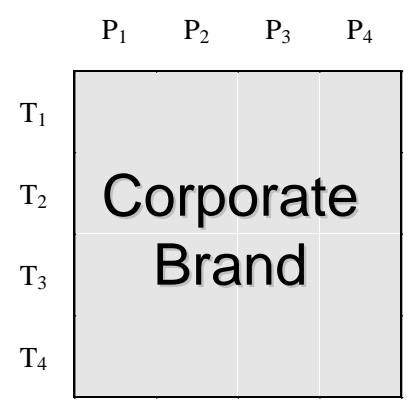

P-branding

\begin{tabular}{|c|c|c|c|c|}
\hline & $P_{1}$ & $\mathrm{P}_{2}$ & $\mathrm{P}_{3}$ & $\mathrm{P}_{4}$ \\
\hline \multirow[t]{2}{*}{$\mathrm{T}_{1}$} & $B$ & $B$ & $B$ & $B$ \\
\hline & $r$ & $r$ & $r$ & $r$ \\
\hline$T_{2}$ & a & a & a & $a$ \\
\hline & $\mathrm{n}$ & $\mathrm{n}$ & $\mathrm{n}$ & $\mathrm{n}$ \\
\hline$T_{3}$ & $\mathrm{~d}$ & $d$ & $d$ & $d$ \\
\hline $\mathrm{T}_{4}$ & 1 & 2 & 3 & 4 \\
\hline
\end{tabular}

T-branding

$\begin{array}{llll}\mathrm{P}_{1} & \mathrm{P}_{2} & \mathrm{P}_{3} & \mathrm{P}_{4}\end{array}$

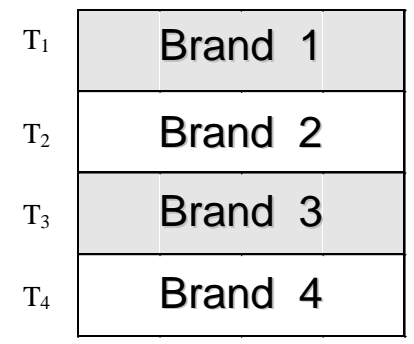

\section{PT-branding}

F-branding

\begin{tabular}{c|c|c|c|c|}
\multicolumn{1}{c}{} & \multicolumn{1}{c}{$\mathrm{P}_{1}$} & \multicolumn{1}{c}{$\mathrm{P}_{2}$} & \multicolumn{1}{c}{$\mathrm{P}_{3}$} & \multicolumn{1}{c}{$\mathrm{P}_{4}$} \\
\cline { 2 - 5 } $\mathrm{T}_{1}$ & B 1 & B 2 & B 3 & B 4 \\
\cline { 2 - 5 } $\mathrm{T}_{2}$ & B 5 & B 6 & B 7 & B 8 \\
\cline { 2 - 5 } $\mathrm{T}_{3}$ & B 9 & B 10 & B 11 & B 12 \\
\cline { 2 - 5 } $\mathrm{T}_{4}$ & B 13 & B 14 & B 15 & B 16 \\
\cline { 2 - 5 } & & &
\end{tabular}

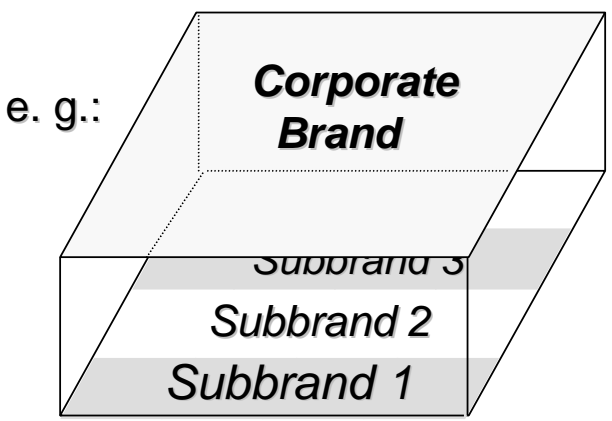

\section{Strategic Brand Concepts and Information Processing}

As research on brand extensions illustrates, success not only depends on the perceived quality of the parent brand (e.g. Aaker and Keller; Paul A. Bottomley and Stephen J. S. Holden), but also on the similarity of products (e.g. Roedder John, Loken, and Joiner; Smith and Park; Sullivan) and the transferability of the image components of the parent brand to the new product (e.g. Aaker and Keller; Bottomley and Holden; Broniarczyk and Alba; C. Whan Park, Sandra Milberg, and Robert Lawson). In fact, a good match between the strategic brand concept and the new product would seem to contribute significantly to the success of a brand extension (Park, Milberg, and Lawson). Park, Jaworski and MacInnis distinguish three strategic brand concepts - "functional", "experiential" and "symbolic brands", to which a fourth concept has been added below, "emotional brands": 
- $\quad$ Functional brand concepts promise a greater product benefit, for example, through technical superiority, greater durability or reliability (see field 1 in Figure 1).

- Symbolic brand concepts (field 2) enable the buyer to express personality, values and status and help to improve self-esteem and social self-presentation (e.g. prestige).

- $\quad$ Experiential brand concepts (field 3) emphasize the sensual experience of the product by building up associations with the five senses - taste, smell, hearing, sight, and touch. This includes the crispiness of potato chips as well as the freshness of toothpaste or the feel of clothes on the skin. Products are often designed to appeal to more than one of the senses. Such is the case with detergent, whose powerful cleaning properties are portrayed synesthetically through smell, color and viscosity.

- $\quad$ Emotional brand concepts (field 4) have been added at this point to categorize brand techniques that appear not to be adequately summarized in the three strategic brand concepts of Park et al. They are, for example, based on a commitment to generally accepted social values (e.g. social responsibility, cultural sponsoring) and advertising techniques of emotional conditioning (e.g. through pictures, music or genetically determined stimulus-response mechanisms). These associations serve to build up sympathy for the brand without - in contrast to symbolic brand concepts - polarizing customers. This form of brand concept is frequently used by market leaders or in product categories where the degree of trust placed in a brand plays an important role (e.g. financial service providers). ${ }^{2}$

With a reasonable degree of plausibility, the motives and benefits as well as the predominant styles of thinking displayed by customers in their buying decisions can be classified according to these four brand concepts:

- $\quad$ Functional brand concepts primarily promise to avoid problems through superior product quality. As this brand concept focuses on the use of central arguments (e. g. product attributes), it should be utilized by companies with leading brands especially in cases where the customer's involvement and product knowledge suffice to enable such arguments to be processed. This style of thinking is described in the literature as "central" (e.g. Petty and Cacioppo), "systematic" (e. g. Chaiken, Wood, and Eagly) or "rational" (Epstein), and can be "integrative" as far as the adopted brand architecture is concerned in two respects: On the one hand, this style of thinking tends to delineate very accurately and focuses on logical connections (Epstein et al., page 329). In cases where a brand encompasses a broad product range, for example, this prevents an excessive degree of psychological overlap between one product and another, evoking unsuitable or undesired associations. On the other hand, a wide product range encompassed by one brand, together with the fact that the brand is purchased by many consumers, are arguments in favor of this brand for functionallyoriented customers (cf. Jennifer Aaker and Durairaj Maheswaran; Amna Kirmani and Akshay R. Rao; Akshay R. Rao, Lu Qu, and Robert W. Ruekert).

- $\quad$ Experiential brand concepts aim to evoke hedonism and pleasure through a sensual product experience and are most closely comparable to the processing style termed "experiential" by Epstein. In many cases, the sensual product experience is based on a largely preconscious processing which works without, or in addition to, rational processing (e.g. Seymour Epstein et al., page 329). It is assumed that this style of thinking works "separatively" as far as brand architecture is concerned: As a consequence of its holistic nature experiential processing tends to overgeneralize and adopts a simple covariance learning which cannot recognize logical barriers between products (cf. Rashmi Adaval; Pawel Lewicki, Thomas Hill, and Maria Czyzewska). A food brand, which the customer has frequently experienced in the form of "sweet" products, will have difficulties launching savory products under the same brand name. In addition, the consumer does not appear to be interested in "compromise products" when it comes to sensual pleasure, but in unique, clear experiences. This desire is expressed in a higher degree of variety seeking among experiential products (J. Jeffrey Inman).

- Symbolic brand concepts serve to maintain or increase self-esteem or to build up a positive picture of oneself in one's social environment. This goal is typically linked to biased processing, creating a highly advantageous self-image or high degree of prestige - often in contrast to the facts and feedback of the social environment (e.g. Aaker; Chaiken, Wood, and Eagly). This biased information processing can be both a

\footnotetext{
${ }^{2}$ The term "emotional" is not entirely accurate in this context, as experiential and symbolic brand concepts among customers also evoke emotions. The following section aims to take the delineation of these four concepts further by applying concepts taken from consumer psychology.
} 
systematic process as well as a superficial one (Serena Chen, David Shechter, and Shelly Chaiken). However, as far as strategic brand concepts are concerned, we can assume that brand managers only rely solely on symbolic brand concepts when the importance of these components is high enough for the customer to enable him/her to think intensively about the social expressiveness of the brand. If we consider the effect on brand architecture strategy, there are two arguments in favor of separative symbolic brand concepts: First and foremost, most consumers - at least in the western world - want to differentiate their own personality from that of others (Hazel Rose Markus and Shinobu Kitayama; Hazel Rose Markus, Shinobu Kitayama, and Rachel J. Heiman). Second, biased information processing is always a highly fragile game, which only works as long as the cue, used manipulatively, (e.g. a prestige brand) is absolutely clear and unmistakable. A brand that does not unequivocally stand for certain values or user imagery will lose its symbolic value.

- Emotional brand concepts try to evoke an emotional attachment to the brand as well as to the community and to impart a sense of familiarity with the brand. In addition to market leaders which appeal to a large proportion of the population, emotional brand concepts tend to be used in cases where there are either no core arguments in favor of the brand, or where the customer is not willing or unable to adequately assess such product differences. Emotional brand concepts are a classical case for so-called peripheral information processing (Petty and Cacioppo), where consumers assess a brand in a cognitively effortless, often emotional way. As is the case with functional concepts, emotional brand concepts also work integratively as far as the brand architecture strategy is concerned: In contrast to symbolic brand positioning, identification with the brand is not motivated by the desire to be different, but rather by the desire to belong socially. Emotional brands therefore work with integrative advertising appeals such as generally accepted social norms or genetically determined stimulus-response mechanisms to ensure that no gap emerges between the brand's various target groups. On the other hand, the emotional attachment to the brand is also a positive signal of trustworthiness that can be applied to a variety of products.

Two further remarks need to be added to complete this system:

- $\quad$ Strategic brand concepts are not linked to specific products. Functional, experiential, emotional or symbolic concepts can be applied to most products. For example, a watch can be mainly functional (e.g. Timex) or can be positioned symbolically (e.g. Rolex, see Park, Milberg, and Lawson). However, there are also products with "built-in" symbolic content such as household goods or sports cars, which are inevitably linked to certain perceptions about typical users. On the other hand, other products are inextricably linked to experiential associations, making purely functional brand images impossible.

- Most brands in reality do not correspond to the ideal "pure" forms, but are a mixture of two or more of these concepts (fields 5 to 9 in Figure 2). These are car brands, for example, which constitute mixed forms of functional (e.g. reliability), symbolic (prestige), emotional (patriotism) or experiential (comfort or the pleasure of driving) brand concepts - depending on emphasis and target group.

$\bullet$

Figure 2 summarizes the four brand concepts with their corresponding consumer benefits and styles of information processing.

\section{"B.A.S.E." - A Brand-Architecture Strategy Explorer}

Building on the four strategic brand concepts and the corresponding consumer benefits and styles of thinking, the Brand Architecture Strategy Explorer (B.A.S.E.), incorporating the following standard strategies, is proposed as an instrument to explore and identify the optimal brand architecture strategy (Fig. 3).

- $\quad$ Companies whose positioning on the markets they serve is purely functional would benefit from a Cbranding strategy. This is frequently the case in the technical goods sector, both in B2B and B2C. The common image denominator between products in closely linked product categories can evoke relatively specific product associations. The wider the product range, the more abstract the common values of the Cbrand will be (e.g., Richard R. Klink and Daniel C. Smith, page 329). Provided there are no incompatibilities of a symbolic or experiential nature, C-brands can unite a wide range of products under one roof, as consumers can get used to extensions which may seem unusual initially (Klink and Smith). Integration via 
the common C-brand through the establishment of brand awareness and brand trust is always an advantage, even if the common denominator of the brand image - in the case of very heterogeneous products, for example - is rather weak. In the case of large submarkets with relatively low costs incurred in brand-building and a high degree of product heterogeneity, it can, however, be worthwhile complementing an abstract Cbrand with specific subbrands at product or target group level. These should signify specific product qualities to the customer, thus facilitating the purchasing decision. In this case, there is some overlap between the definitions of C-branding and F-branding in this field (see the grey shaded area between the dotted lines in Figure 3).

- $\quad$ The same is true for companies with a portfolio consisting of products with an emotional positioning as well as for a product portfolio with a mixture of functional and emotional concepts. As is apparent from the previous section, this does not give rise to any incompatibilities between the various products offered or target groups served. However, in this case as well, too great a degree of product heterogeneity might make it seem expedient to create subbrands for larger submarkets in addition to the C-brand, which once again overlaps with F-branding.

- $\quad$ If the range of a company's products includes a number of concepts with various symbolic traits, B.A.S.E. recommends a T-branding strategy whose target group brands are defined through socio-demographic (age, income) and/or psychographic characteristics (lifestyle, values). These symbolic target group brands can include a wide range of products. For example, prestige brands have little difficulty in uniting a great variety of products under one brand, as long as the image of the typical brand users is uniform and continues in the direction desired by the target group (cf. Park, Lawson, and Milberg; Park, Milberg, and Lawson). The transition to F-branding is smooth in this case, too, although the indicators are different here. Provided the groups targeted are not too heterogeneous, but the costs of brand management are high in comparison to the consumers' willingness to pay a premium for the added symbolic value of the brand, it can make sense to integrate target markets to a certain extent through hierarchical F-branding.

- $\quad$ B.A.S.E. proposes a P-branding strategy for a range of products with different experiential characteristics. Even if the product categories covered by such P-brands can be very broad on occasion (e.g. all sweettasting foodstuffs), they are limited by the physical properties of the product category due to their experiential nature. As long as the brand does not make symbolic promises in addition to experiential ones (e.g. gift confectionery), using the same brand name for very different target groups, as illustrated above, should not present a problem (e.g. sweets for young and old).

- If a company's product range includes combinations of symbolic and experiential brand concepts, it should turn to PT-branding, the most separative (and most costly) form of brand architecture. Otherwise, the brands will either lose their symbolic credibility (as is the case with P-brands) or their experiential character (T-brands).

- Mixtures of symbolic or experiential brand concepts, on the one hand, and functional or emotional concepts, on the other, as well as mixtures which contain three or all four of these added value components, require the complex brand architecture of F-branding, integrating a diverse range of combinations of $\mathrm{C}$-, P-, T- and PT-brands in a hierarchical concept. If we intend, for example, to target a certain number of groups with different symbolic demands, but with the same high functional demands, a functional C-brand is recommended as a guarantee of technological expertise and quality, beneath which T-subbrands can be distinguished symbolically for different target groups. Which of these levels is given stronger emphasis will depend on the weighting of functional and symbolic buying motives. If symbolic motives dominate, an endorsing C-brand is recommended together with strong symbolic T-subbrands (cf. Aaker and Joachimsthaler, page 104). If the functional motive has the upper hand, a strong C-brand is recommended as a "master brand", with supplementary T-subbrands. Similarly, combinations of emotional C-brands, experiential Pbrands and PT-brands can also be created. 
Figure 2: Strategic brand concepts, consumer benefit and processing style

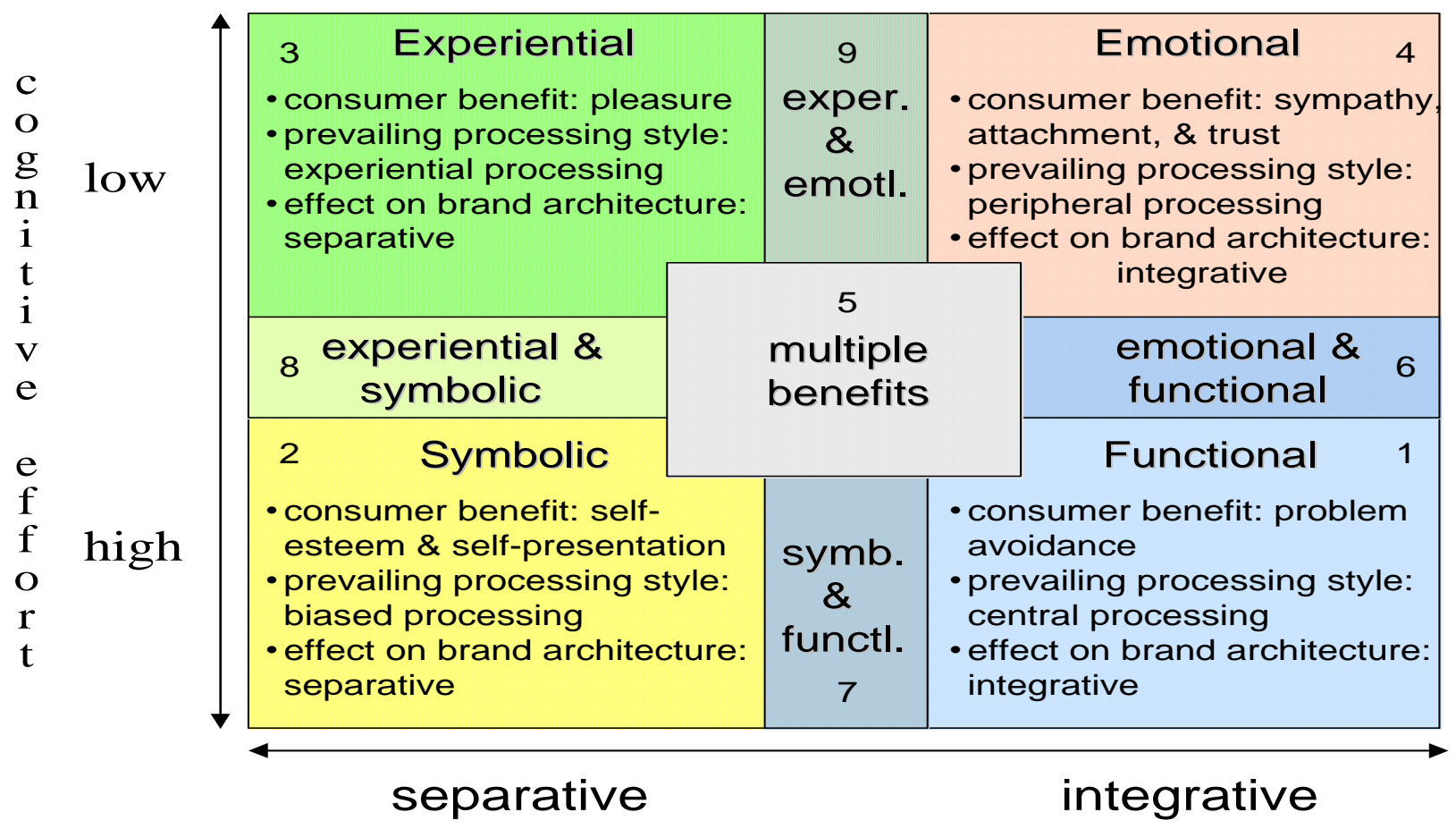

Figure 3: B.A.S.E. - A brand-architecture strategy explorer

\begin{tabular}{|c|c|c|}
\hline $\begin{array}{l}\text { Experiential } \\
\text { P-branding }\end{array}$ & $\begin{array}{c}\text { e. \& e. } \\
\text { F- } \\
\text { branding }\end{array}$ & $\begin{array}{l}\text { Emotional } \\
\text { C-branding }\end{array}$ \\
\hline $\begin{array}{l}\text { experiential \& symb. } \\
\text { PT-branding }\end{array}$ & \multirow[t]{2}{*}{$\begin{array}{l}\text { multiple benefits } \\
\text { F-branding }\end{array}$} & $\begin{array}{l}\text { emotional \& functl. } \\
\text { C-branding }\end{array}$ \\
\hline Symbolic & & Functional \\
\hline T-branding & $\begin{array}{c}\text { F- } \\
\text { branding } \\
\text { s. \& f. }\end{array}$ & C-branding \\
\hline
\end{tabular}




\section{Discussion}

By linking five brand architecture strategies with the strategic brand concept model and with human information processing models, the Brand Architecture Strategy Explorer proposes standard brand architecture strategies for various combinations of strategic brand concepts.

The considerations that have gone into B.A.S.E. incorporate a significant number of empirical studies, which are summarized in the form of a uniform model. An empirical test of B.A.S.E. should not only examine the customer side but ought also to consider company data such as brand management costs per unit sold and profit, to monitor the validity of standard strategies.

Some considerable limits should be noted on the theoretical side:

- $\quad$ The standard strategies in B.A.S.E. maximize the success of the company's brand(s) in customer terms. They do not involve further consideration of the company's positioning with regard to other stakeholder groups such as current or future employees or shareholders. All in all, the involvement of additional stakeholders in brand architecture strategy is an even stronger argument in favor of C-branding. On the other hand, the goal of avoiding conflicts in the distribution channel or the intention to utilize buyer's surplus through price differentiation are arguments in favor of a greater number of brands than B.A.S.E. would recommend.

- $\quad$ B.A.S.E. is based on a typical cost structure of different brand architectures, for which highly integrated brand architecture strategies are more cost-effective than highly separated strategies (cf. e.g. Aaker and Joachimsthaler, page 123; Kapferer, page 209). The extent of this cost benefit can, however, vary from sector to sector, and the significance of this cost benefit depends, among other factors, on the size of the (sub)market and the price sensitivity of customers. Larger markets with less price-sensitive consumers in sectors where customer subgroups can be easily and selectively reached justify a greater number of brands. This results in a grey area in the standard strategy recommendations between C-branding and F-branding, and between P- or T-branding and F-branding.

- Many companies have a mixture of functional, experiential, symbolic and emotional products. But even in this case, however, it is possible to develop standard strategies based on B.A.S.E. relatively easily. These strategies, for example, could unite the products with functional or emotional emphasis through CB.A.S.E. is a model based on psychological assumptions, which may only be valid in western cultures. In eastern cultures, the motive for symbolic consumption tends to be the desire to belong rather than to be different (e.g. Markus and Kitayama; Markus, Kitayama, and Heiman). This could explain the emergence of very broad C-brands in Japan (e.g. Kapferer, page 128). In other cultures, which, in comparison to western cultures, pay greater attention to developing the capacity to know one's own body and its sensual experiences, wider experiential umbrella brands could be successful.

- $\quad$ All in all, B.A.S.E. is an explorative instrument that can provide assistance in making strategic brand architecture decisions, bearing in mind its limitations. However, it does not replace the fine-tuning required in the specific design of the brand architecture, nor the particular caution to be exercised when crossing cultural boundaries.

\section{References}

1. Aaker, David A. and Erich Joachimsthaler (2000), Brand Leadership. New York: The Free Press.

2. Aaker, David A. and Kevin Lane Keller (1990), "Consumer Evaluations of Brand Extensions," Journal of Marketing, 54, 27-41.

3. Aaker, Jennifer and Durairaj Maheswaran (1997), "The Effect of Cultural Orientation on Persuasion," Journal of Consumer Research, 24 (December), 315-28.

4. $\quad$ Aaker, Jennifer L. (1999), "The Malleable Self: The Role of Self-Expression in Persuasion," Journal of Marketing Research, 36 (February), 45-57.

5. Adaval, Rashmi (2001), "Sometimes It Just Feels Right: The Differential Weighting of Affect-Consistent and Affect-Inconsistent Product Information," Journal of Consumer Research, 28 (June), 1-17. 
6. Bottomley, Paul A. and Stephen J.S. Holden (2001), "Do We Really Know How Consumers Evaluate Brand Extensions? Empirical Generalizations Based on Secondary Analysis of Eight Studies," Journal of Marketing Research, 38 (November), 494-500.

7. Broniarczyk, Susan M. and Joseph W. Alba (1994), "The Importance of the Brand in Brand Extension," Journal of Marketing Research, 31 (May), 214-28.

8. Chaiken, Shelly, Wendy Wood, and Alice Eagly (1996), "Principles of Persuasion," in Social Psychology: Handbook of Basic Principles, E. T. Higgins and Arie W. Kruglanski, eds. New York: The Guilford Press.

9. Chen, Serena, David Shechter, and Shelly Chaiken (1996), "Getting the Truth or Getting Along: AccuracyVersus Impression Motivated Heuristic and Systematic Processing," Journal of Personality and Social Psychology, 71, 262-75.

10. Epstein, Seymour (1983), "The Unconscious, the Preconscious, and the Self-Concept," in Psychological Perspectives on the Self, Vol. 2, Jerry Suls and Anthony G. Greenwald, eds. Hillsdale, New Jersey: Lawrence Erlbaum.

11. Epstein, Seymour, Abigail Lipson, Carolyn Holstein, and Eileen Huh (1992), "Irrational Reactions to Negative Outcomes: Evidence for Two Conceptual Systems," Journal of Personality and Social Psychology, 62, 328-39.

12. Erdem, Tülin (1998), "An Empirical Analysis of Umbrella Branding," Journal of Marketing Research, 35 (August), 339-51.

13. Inman, J. Jeffrey (2001), "The Role of Sensory-Specific Satiety in Attribute-Level Variety Seeking," Journal of Consumer Research, 28, 105-20.

14. Kapferer, Jean-Noel (1999), Strategic Brand Management: Creating and Sustaining Brand Equity Long Term. London: Kogan Page.

15. Keller, Kevin Lane (1998), Strategic Brand Management: Building, Measuring, and Managing Brand Equity. Upper Saddle River, New Jersey: Prentice-Hall.

16. Keller, Kevin Lane and David A. Aaker (1992), "The Effects of Sequential Introduction of Brand Extensions," Journal of Marketing Research, 29, 35-50.

17. Kirmani, Amna and Akshay R. Rao (2000), "No Pain, No Gain: A Critical Review of the Literature on Signaling Unobservable Product Quality," Journal of Marketing, 64 (April), 66-79.

18. Klink, Richard R. and Daniel C. Smith (2001), "Threats to External Validity of Brand Extension Research," Journal of Marketing Research, 38 (August), 326-35.

19. Laforet, Sylvia and John Saunders (1999), "Managing Brand Portfolios: Why Leaders Do What They Do," Journal of Advertising Research, 39 (January/February), 51-66.

20. Lewicki, Pawel, Thomas Hill, and Maria Czyzewska (1994), "Nonconscious Indirect Inferences in Encoding," Journal of Personality and Social Psychology, 123, 257-63.

21. Markus, Hazel Rose and Shinobu Kitayama (1991), "Culture and the Self: Implications for Cognition, Emotion, and Motivation," Psychological Review, 98, 224-53.

22. Markus, Hazel Rose, Shinobu Kitayama, and Rachel J. Heiman (1996), "Culture and "Basic" Psychological Principals," in Social Psychology: Handbook of Basic Principles, E. Tory Higgins and Arie W. Kruglanski, eds. New York: The Guilford Press.

23. Morrin, Maureen (1999), "The Impact of Brand Extensions on Parent Brand Memory Structures and Retrieval Processes," Journal of Marketing Research, 36 (November), 517-25.

24. Park, C. Whan, Bernard J. Jaworski, and Deborah J. MacInnis (1986), "Strategic Brand Concept Management," Journal of Marketing, 50 (October), 135-45.

25. Park, C. Whan, Robert Lawson, and Sandra Milberg (1989), "Memory Structure of Brand Names," Advances in Consumer Research, 16, 726-31.

26. Park, C. Whan, Sandra Milberg, and Robert Lawson (1991), "Evaluation of Brand Extensions: The Role of Product Feature Similarity and Brand Concept Consistency," Journal of Consumer Research, 18, 185-93.

27. Petty, Richard E. and John T. Cacioppo (1986), Communication and Persuasion: Central and Peripheral Routes to Attitude Change. New York: Springer Verlag.

28. Rao, Akshay R., Lu Qu, and Robert W. Ruekert (1999), "Signaling Unobservable Product Quality Through a Brand Ally," Journal of Marketing Research, 36 (May), 258-68.

29. Roedder John, Deborah, Barbara Loken, and Christopher Joiner (1998), "The Negative Impact of Extensions: Can Flagship Products Be Diluted?" Journal of Marketing, 62 (January), 19-32. 
30. Saunders, John and Fu Guoqun (1997), "Dual branding: how corporate names add value," Journal of Product \& Brand Management, 6, 40-8.

31. Smith, Daniel C. and C. Whan Park (1992), "The Effects of Brand Extensions on Market Share and Advertising Efficiency," Journal of Marketing Research, 29 (August), 296-313.

32. Sullivan, Mary (1990), "Measuring Image Spillovers in Umbrella-branded Products," Journal of Business, 63, 309-29.

33. Swaminathan, Vanitha, Richard J. Fox, and Srinivas K. Reddy (2001), "The Impact of Brand Extension Introduction on Choice," Journal of Marketing, 65 (October), 1-15. 